$\xi=-1$

\title{
Predominant Washback of the General Secondary English Examination on Teachers
}

\author{
Yahya Ameen Tayeb ${ }^{1 *}$, Mohd Sallehhudin Abd Aziz ${ }^{2}$, Kemboja Ismail ${ }^{3}$ \\ ${ }^{1}$ English Department, Faculty of Education, Hodeidah University, Zabid - Hodeidah, Yemen \\ ${ }^{2,3}$ School of Language Studies and Linguistics, Faculty of Social Sciences and Humanities, Universiti Kebangsaan Malaysia, 43600 \\ UKM, Bangi Selangor, Malaysia \\ *Corresponding author E-mail: yahyaamin73@yahoo.com
}

\begin{abstract}
General Secondary English Examination (GSEE) is the highest secondary school exit test run by the Ministry of Education, Yemen. Due to the significance of the exam being the foundation of the students' future, teachers are only preoccupied with how to help students get high marks in this final examination to be eligible to join university. The aim of this study is to investigate the dominant wash back effect of the GSEE on Yemeni teachers who are highly engrossed by the test. The study focuses on four pedagogical dimensions namely teachers' teaching methods, content assessment, attitudes and motivation. Mixed mode approach (qualitative and quantitative methods) was applied using classroom observations, semi-structured interviews, group discussions and a questionnaire of 72 items administered to 46 English teachers. NVivo10 was used to analyse the qualitative data. SPSS/V22 was used for analysing the quantitative data in which the Cronbach's Alpha reached (.88). The results revealed that the test had a great influence on teachers $(\mathrm{P}<.001)$ mainly on their teaching methods. Triangulation with the qualitative analysis confirmed equivalent implications. The study contributes a clear evidence of the powerful exam washback on the factors of the language learning practices and its influence on how and what teachers teach.
\end{abstract}

Keywords: Washback; GSEE; Yemen; Teaching Methods; Content Assessment; Teachers' Attitudes; Teachers' Motivation

\section{Introduction}

As in many developing countries, the Yemeni educational system is a test-driven one. The General Secondary English Examination (GSEE) is the first standardized test administered at the end of the last level of the secondary school. As an important prerequisite for the tertiary stage, English is the most prominent subject for which learners have to spend four hours answering the test questions in two sessions. Since the GSEE is perceived as the vehicle by which students can reach their future goal, they try to exploit all possibilities to help themselves overcome the difficulties of the test. At the same time, teachers devote their efforts to deliver the prescribed syllabus using commercial booklets/hand-outs containing many past years' tests to provide practice for their students.

Accordingly, teachers spend more efforts to condense the prescribed syllabus into commercial booklets/handouts entailed with many tests of the previous years so that they make it easier for learners to pass the exam. In this way, the teachers, as Prodromou (1) argues, are trapped in a cycle of examination preparation and they consider the humanistic and communicative methodologies as unaffordable luxuries. This illustrates that the GSEE is the main obstacle that stands in the way of learners in Yemen. Based on the researchers' experience, it is the GSEE that hinders the English teachers from developing their traditional teaching methods where they find themselves bound to the conditions and the instructions of the test designers. They have no choice except teaching to the test although they realize that the exam is a grammar-based test which pays no attention to the communicative skills. Hence, the main aim of this paper is to shed some light on the extent of the washback effect of the GSEE on the secondary school English Teachers.

\section{Literature Review}

Applied linguists to date have variously defined the term washback $(2,3)$ or backwash $(4,5)$. They broadly defined it as the influence of testing on teaching and learning (5-7). Many recent researchers cited the definition by Messick (8)who refers to the notion of washback as "... the extent to which the introduction and use of a test influences language teachers and learners to do things they would not otherwise do that promote or inhibit language learning" (8). However, the term washback has become a prevailing phenomenon in the field of education especially in the last two decades.

Broadly, the different notions of washback as an educational phenomenon can generally be extracted into four key definitions of the washback concepts. The first is the concept of 'washback effect,' which refers to the impact tests have on both teaching and learning. The second deals with the concept of 'measurementdriven instruction,' which refers to the idea that learning should be driven by testing. The third focuses on the the concept of 'curriculum alignment' which focuses on the relationship between the teaching syllabus and testing. The fourth, and the last is the concept of 'systemic validity,' which interrelates tests into the educational system. The discussion of the GSEE washback in Yemen and its influence on the English teachers encompasses all these notions (9).

As the arrow hits the teaching-learning area (schools), the concern must be more on this context. In other words, teachers 
and learners are the first and the mostly affected people by the examination washback. On the part of teaching, tests have a great impact on the lives of teachers. Their teaching methods and content assessment, attitudes and motivation are affected by the tests in line with their perceptions of testing and its consequences $((9$, 10). This can be seen clearly in their actual performance of teaching in classroom, which in turn has its consequences on the outer context (i.e. the stakeholders on the part of the macro level. Figure 1 , by Nguyen, Griffin (10), centralizes this notion.

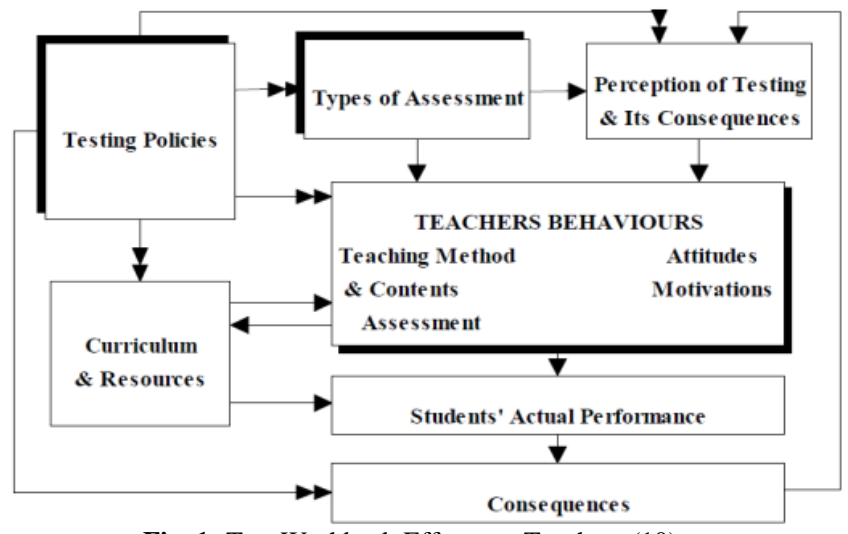

Fig. 1: Test Washback Effects on Teachers (10)

\subsection{Conceptual Framework}

The following model (Figure 2) illustrates the washback effect of the GSEE on teachers in the Yemeni context. It has been devised in the light of the previous related washback studies $(10,11)$. Four factors are affected by the test, namely teaching methods, content assessment, attitudes and motivation.

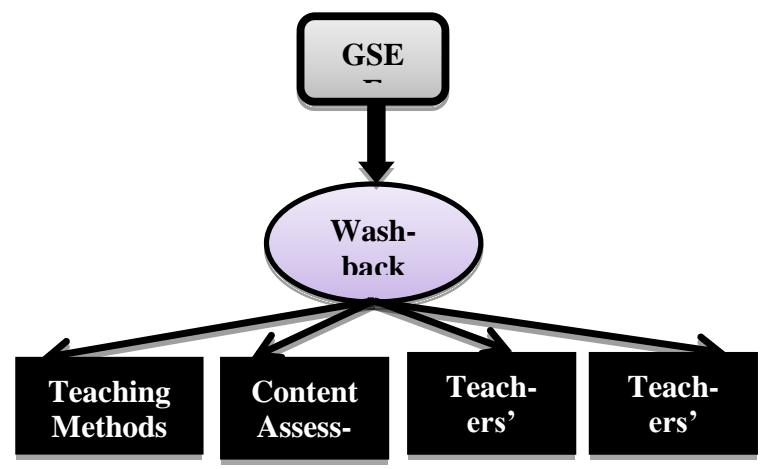

Fig. 2: GSEE Washback on Teachers

\section{Methodology}

\subsection{Approaches and Instruments}

In this study, an exploratory triangulation design is applied where the research methodology is executed via three stages beginning with practicing classroom observations, followed by carrying out semi-structure interviews and ending with conducting a questionnaire. Hence, the study uses both qualitative and quantitative methods. Since the main purpose was to deeply investigate the washback phenomenon in the Yemeni context, a total of 39 classes were observed in seven schools (of both male and female studnts), semi-structured interviews were carried out with 15 teachers who taught English for the 3rd secondary (12th grade) students. The 15 teachers were experts in the GSEE and they were teaching English for the $3^{\text {rd }}$ secondary classes for 5-15 years. As these teachers were affected by the washback phenomenon for a long time ( $>5$ years) in comparison to younger teachers in same schools, they contributed actively by describing in detail their experiences about the test. As a result, the qualitative data collect- ed via the classroom observations and the interviews served as a better and clearer description, and explanation of the washback effect on Yemeni teachers.

The gender of the teachers and the location of schools were taken into consideration. In Yemen, it is common to see male teachers teaching boys in boys' schools and female teachers teaching girls in girls' schools (9). Hence, the participants were systematically chosen from male and female secondary schools scattered in urban and rural areas in Yemen.

Axiomatically, when talking about classroom observation, the picture which comes into one's mind is that an observer would get two valuable opportunities, optical and auditory. The first is of visual nature including objects and movements that can be seen such as materials used, seats arrangement, number of participants and who mostly/rarely has part in the classroom interaction. This was implemented by developing a coding scheme to suit the Yemeni context based on some previous studies $(12,13)$. The main aim of using classroom observation was to get clear insights about the teaching-learning characteristics that could be elicited through the interaction between the learners and their teachers in the classroom. The focus of the observation was on: 1) skills mainly taught and learnt;2) kinds of activities mainly used; 3) communicative features used in classroom activities; and 4) main and supplementary materials used to prepare students for the GSEE.

The main purpose of carrying out the interview with the English teachers was to gain more accurate descriptive data because they are the most affected stakeholders by the GSEE. A total of 10 questions constituted the interview protocol. All of the questions were designed as per the four pedagogical dimensions related to the teachers namely: 1) teaching methods; 2) content assessment; 3) teachers attitudes; and 4) teachers' motivation. Some supplementary extemporaneous questions were raised when it was perceived that more elaboration could be elicited for further understanding.

Based on the interviewees' description of the actual status of the teaching processes under the washback effect of the GSEE and their interpretations of the consequences the test has on the stakeholders, a questionnaire was constructed and administered to 46 secondary school English teachers who were teaching the $12^{\text {th }}$ grade (last 3rd level of the secondary school). The questionnaire items were elicited throughout the interviews and based on previous studies $(14,15)$. The use of the questionnaire constituted the quantitative method, which was descriptively analysed using SPSS version 22.

As mentioned earlier, the questionnaire design constituted two main parts, whereby all the items were constructed in English. The first part of the questionnaire was specified for the respondents' demographic data where there were six categories devoted to find out their gender, age, English language proficiency and so forth. The second part consisted of 72 items. This part essentially dealt with eight pedagogical dimensions: four of them concerned the teachers (teaching methods, content assessment, teachers' attitudes and teachers' motivation) and four concerned the students (learning styles, learning activities, attitudes and motivation). Due to the space limitation, only those factors related to teachers have been considered in this paper. All of the items were designed on a fivepoint Likert scale of agreement where $1=$ strongly agree, $2=$ agree, $3=$ undecided $=4=$ disagree and $5=$ strongly disagree.

\subsection{Participants}

Based on (11) who argued that social research must be based on selection rather than sampling, English teachers were selected for the interview and for the questionnaire survey. Specifically, as washback is an information-rich in nature, it becomes normal to select various groups of participants (i.e., selecting teachers from different schools in different rural-urban areas) rather than a single population. More specifically, the teachers who taught English in the 3rd secondary classes were targeted because they were the immediate stakeholders affected by the GSEE. In this way, their 
responses to the questions were more likely to be valid and reliable because they were directly affected by the test.

In addition to the classroom observations, the participants were purposively chosen ac

cording to the needs of the study. Firstly, fifteen Yemeni English teachers who have been teaching the $3^{\text {rd }}$ secondary classes were chosen to participate in one-to-one interview. The interviewees' ages were between 30-50 years old, eleven males and four females. Each interview session lasted for about 20-40 minutes. This range of time periods for interviews may seem to be short but it covers the whole themes of the study through the use of the interview protocols. Most of the teachers have more than 10 years of teaching experience. This makes it worth to intensely consider their viewpoints about the effect of the GSEE. The teachers comprise of different demographical layers moving from the highest standardized schools in the main town to the mid-standardized schools in the secondary towns and ending with the lowest standardized schools in the rural area. Throughout the interviews, the four dimensions were subjected for discussion: teaching methods (TM), content assessment (CA), teachers' attitudes (TA) and teachers' motivation (TMO). The participants' profiles have been summarized in Table 1.

Table 1: Model for Paper

\begin{tabular}{|l|l|l|l|l|}
\hline No. & $\begin{array}{l}\text { Teachers' } \\
\text { codename }\end{array}$ & Gender & $\begin{array}{l}\text { Teaching } \\
\text { experience } \\
\text { (Years) }\end{array}$ & $\begin{array}{l}\text { Locality } \\
\text { (Main/Secondary } \\
\text { town/ Rural) }\end{array}$ \\
\hline 1 & AA & M & 13 & M. Town \\
\hline 2 & AD & M & 8 & Rural \\
\hline 3 & AG & M & 13 & S. Town \\
\hline 4 & AM & M & 22 & M. Town \\
\hline 5 & DH & F & 12 & S. Town \\
\hline 6 & EH & M & 22 & M. Town \\
\hline 7 & GY & M & 2 & Rural \\
\hline 8 & HM & F & 13 & S. Town \\
\hline 9 & HY & M & 11 & M. Town \\
\hline 10 & KT & M & 15 & S. Town \\
\hline 11 & MG & M & 8 & Rural \\
\hline 12 & MO & M & 14 & S. Town \\
\hline 13 & SG & F & 8 & S. Town \\
\hline 14 & SK & F & 11 & S. Town \\
\hline 15 & SZ & M & 23 & Rural \\
\hline
\end{tabular}

In addition to the interviews, a survey was administered to 46 English teachers to get their viewpoints about the GSEE and its influence on the Yemeni teachers. Four major elements were considered to be scrutinized precisely. Each element was covered by eight items arranged according to Likert scale of agreement. As sampling was purposive, where the respondents were only the teachers who teach English in the 3rd secondary classes, and the purpose of the questionnaire was for triangulation with qualitative data, 60 copies of the survey were specifically distributed to the teachers of English of the 3rd secondary classes. Out of the 60 copies of the questionnaire, 46 were returned constituting a return rate of $76.7 \%$.

The great majority of the respondents were Bachelor's Degree holders in English language (41 teachers) reaching 89.1\%, while only three participants were Postgraduate Teaching Diploma holders with a percentage of $6.5 \%$. Only one respondent was a holder of Master's Degree (2.2\%) and another was a holder of another certificate (the $5^{\text {th }}$ choice). Due to reasons of confidentiality, the researchers did not provide the name of any of the participants. Table 2 illustrates participants' qualifications.

Table 2: Participants' Qualification

\begin{tabular}{|l|l|l|}
\hline Qualifications & Frequency & Percentage \\
\hline Bachelor's degree & 41 & $89.1 \%$ \\
\hline Postgraduate teaching diploma & 3 & $6.5 \%$ \\
\hline Master's degree & 1 & $2.2 \%$ \\
\hline Others & 1 & $2.2 \%$ \\
\hline Total & 46 & 100.0 \\
\hline
\end{tabular}

In relation to the respondents' qualification, they were also asked to provide their experience through choosing the appropriate yearset for their teaching. In the questionnaire, each participant would have to tick/choose only one out of five choices: 1) one year; 2) 25 years; 3) 6-9 years; 4)10-14 years and 5) 15 years and above. The results showed that the teachers proportion differences among the $2^{\text {nd }}, 3^{\text {rd }}$ and $4^{\text {th }}$ sets are moderate $(32.6 \%, 26.1 \%$ and $28.3 \%$ respectively) and they were widely high comparing to the $1^{\text {st }}$ and the $5^{\text {th }}$ sets $(4.3 \%$. and 8.7 respectively). In a sense, a total of 15 teachers were 2-5 years experienced, 12 were 6-9 years and 13 were within 10-14 years teaching English. On the other hand, only two fresh teachers participated symbolizing the extreme negative tail of seniority and four teachers were of 15 years and above experience constituted the extreme positive tail of seniority. Figure 3 summarizes the percentages of the participants and visualizes the concepts of the teachers' period of teaching English.

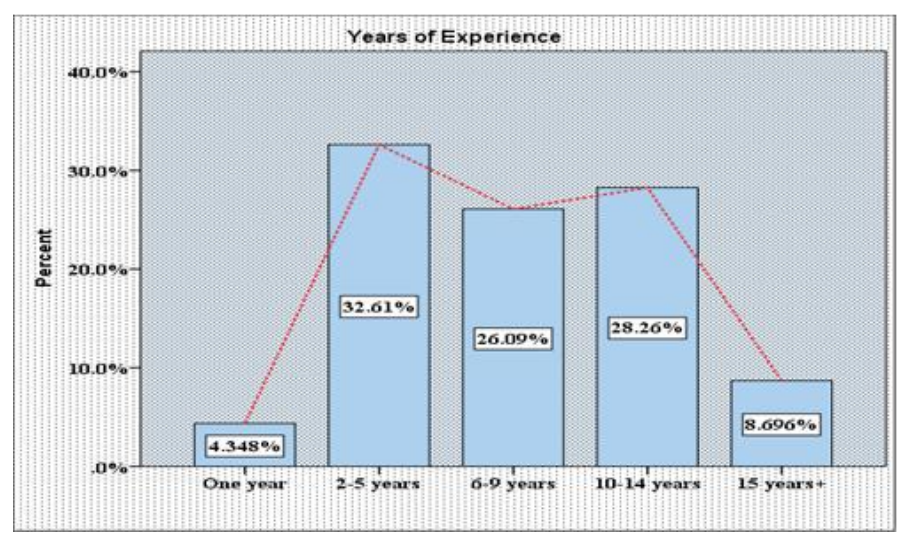

Fig. 3: Years of Teaching Experience

\section{Results and Findings}

As has been mentioned earlier, qualitative approach was the backbone of this study. This is because the researchers have direct access to see many aspects of teaching and learning on the ground in contrast to what the teachers say in their self-reported questionnaires. For example, the researchers had the opportunity to inspect the classroom activities under the influence of the GSEE and closely monitoring the surrounding environment inside and outside the schools. Generally, it was through the classroom observations that the researchers elicited the actual impact of the test on teaching methods, course content, attitudes and motivation of the teachers. Additionally, it was directly observed on how teachers and learners were all working for the GSEE albeit gender segregation, geographical diversity and schools standardization (i.e., school historical reputation).

As GSEE is a paper-and-pencil test and it is the major concern for teachers and learners, it was observed that the focus was mainly on reading and writing. Teachers concentrate more on the reading and writing skills where 11 out of the 39 classes were devoted for this purpose. Similarly, as GSEE is a grammar-oriented and language structure exam, 10 classes were specified for grammar followed by vocabulary for which 4 classes were devoted. Regarding the oral-aural skills, only two classes were observed practicing speaking and listening, see Table 3.

Table 3: Frequency and Percentage of the Language Skills and Structure Classroom Observation Study of (39 Lessons)

\begin{tabular}{|l|l|l|l|}
\hline \multicolumn{2}{|l|}{ Subject/Topic Taught } & Frequency & Percentage \\
\hline & Oral & 2 & $5.1 \%$ \\
\hline & Grammar & 10 & $25.6 \%$ \\
\hline Mock Examinations & 12 & $30.8 \%$ \\
\hline Reading and Writing & 11 & $28.2 \%$ \\
\hline Vocabulary & 4 & $10.3 \%$ \\
\hline Total & 39 & $100 \%$ \\
\hline
\end{tabular}


In the following sections, the four factors of teaching have been manipulated according to teachers' viewpoints. As mentioned earlier, the four pedagogical dimensions (i.e., teaching methods, content assessment, teachers' attitudes and teachers' motivation) were focused on. The software, NVivo (version 10) was helpful in organizing the ideas of the interviews using codes and nodes.

\subsection{GSEE Washback on Teachers' Teaching Methods (TM)}

Teaching Methods (hereinafter referred to as TM) is the first factor around which the questions were asked. Almost all the interviewees agreed that TM is influenced by the GSEE and teachers are teaching English for the sake of the test and not for learning the language. According to AD, the GSEE "influences the ways a teacher teaches students because their minds should be preoccupied with the exam's day". Hence, the $3^{\text {rd }}$ secondary class English teacher is obliged to tailor the way of teaching towards the test. $\mathrm{AD}$ reported that "teachers do not care about the real classroom learning and whether their students have acquired the language or not. They think of how to help the students pass the exam."

According to most of the interviewees, TM is a very important element that should be adapted according to the test. For example, AM argued that TM "is very important because it makes teachers concentrate only on the test." This proves that teaching is not for learning but for testing, because speaking skill is almost ignored albeit its importance to be acquired through the teachers. Teachers see that there is no need for the aural-oral skills because GSEE is a paper-and-pencil test.

Hence, it could be stated that GSEE makes TM unique in the 3rd secondary level compared to the whole previous lower levels. DH asserted that a particular TM must be used "to prepare students to be ready and able to answer the test (questions) at the end of the year." When the interviewee was asked why TM should be different in the 3rd level, the answer was "they are different, because, for example, in the second secondary classes, the teacher himself is the one who makes the exam or takes the decision and he just follows himself in these classes." Additionally, EH strongly affirmed that a teacher "must make his teaching methods suitable for the exam and make students get familiar with this exam." GY tried to interpret the reason beyond adopting TM according to the GSEE and the reason of why teachers teach students according to the way of the exam claiming that the teachers' purpose is how to make their students get high marks to be admitted in the university. On the contrary, some of the interviewees claimed that no much concern is paid to the TM since many students consider their own ways of how to get high marks. Considering this issue, a serious question might be arisen as what way/s students can follow to get higher marks in the GSEE? Rationally, cheating is the most preferred way especially for lazy students. Again, why this happens? HM argued that the phenomenon of cheating especially in the far rural area affects the teachers passively. They find themselves in a situation where their efforts on teaching their students almost have no benefit because students find cheating as the weapon by which they can face the violence of the GSEE. For some students, thinking about the ways of cheating is better than attending classes, listening to their teachers and interacting with their active classmates. Teacher HM lamentably commented on this regard saying that "it becomes more boring especially when the majority of students are absent during the year (of $3^{\text {rd }}$ secondary).

At this point, the situation seems to be controversial. The teachers were thinking about the most appropriate TM that could attract their students and simplify the subject matter for their students. In the contrast, students viewed that teaching is not as helpful as cheating in achieving high marks in the GSEE. Thus, according to their views, they should think about their own methods to implement this target, which is educationally a harmful phenomenon. Throughout the viewpoints presented above, one can elicit that the teachers were forced to teach according to the test. This provided a clear answer for why $31 \%$ of the classes were about mock exami- nations during the classroom observations. The teachers specified around a third of their classes for explaining the exam for two reasons. The first, they felt that it is their role to simplify the test to the students showing them how it is constructed and how questions could be answered. The second, they tried helping the students overcome the difficulties of the exam and in case they succeed in making their students attend classes and get interested in learning, then, the students would indirectly be protected from the cheating phenomenon.

In sum, it could be elicited that what mostly happens in the 3rd secondary classes is somehow controversial and unobvious. This is so because, according to the classroom observations and interviews, the teachers seek what could be called as 'testing methods' rather than teaching methods.

For the purpose of triangulation, the same factor (i.e., teaching methods) was included in the questionnaire. It contains eight items and all were on a five-point Likert scale of agreement where: $1=$ Strongly Agree (SA), 2= Agree (A), 3= Undecided (*), 4= Disagree (D), $5=$ Strongly Disagree (SD). However, while making the analyses, the first two choices were considered as one concept indicating agreement $(\mathrm{SA}+\mathrm{A}=\mathrm{A})$ as positive responses while the last two choices were also dealt with as one concept indicating disagreement $(\mathrm{D}+\mathrm{SD}=\mathrm{D})$ as negative responses. Finally, a table for more statistical details accompanies the description of each theme.

As for the TM theme, eight items were specified for diagnosing the washback effect on this teaching factor. The eight items were headed by a leading question: "what are the major changes you are likely to make in you teaching if your teaching methods in the $3 \mathrm{rd}$ secondary classes are different from those you use in other classes (for example 1st and 2nd secondary classes) because of the impact of the public examination (GSEE)?". Almost all the questionnaire statements were composed as if they were questions. For example, q2.2.1 refers to the first statement in the second question of the second part. As for all the questions of the second part of the questionnaire, the eight statements, of each question, were ranked according to the five-point Likert scale of agreement. However, referring to the results, it was found that responses to the third choice (i.e., undecided) were very low $(>2.2,<4.3)$; that is why it was excluded from the analysis and where available it was mentioned using $(*)$, see Table 4 .

The first statement (q2.2.1) probed whether the respondents believed that they teach according to the test format. The results showed that $71.7 \%$ of the respondents believed that they should use their TM according to the GSEE (strongly agree or agree), while only $28.2 \%$ of them viewed (strongly disagree or disagree) that they adapt their TM according to the course. Exceeding this proportion, for $\mathrm{q} 2.2 .2,95.6 \%$ of the respondents agreed that their TM mainly focus on grammar and vocabulary, while only $4.3 \%$ viewed that they consider language skills rather that language structure. To inquire whether the participants put more stress on role play and group discussion inside classroom as important processes for language learning, q2.2.3 reflected that $84.4 \%$ agreed for that, while $15.2 \%$ disagreed which implied that they see that GSEE is that main target and other processes are just subsidiary in the 3rd secondary class. The fourth statement (Q2.2.4) was drawn to elicit if the teachers made more emphasis on reading and writing skills. The results showed that $89.2 \%$ supported the emphasis on reading and writing due to their importance for the GSEE as a paper-pencil test. The participants who disagreed to this point constituted only $10.9 \%$.

Consequently, q2.2.5 inquired if the participants encourage students to participate in class, while $\mathrm{q} 2.26$ probed into their opinions about adapting new TM in classroom (e.g., exploit the effect of the exam on the students by involving them to participate and use the language inside the class). The results showed high proportions for both statements where $97.8 \%$ agreed for encouraging students to participate in class and $91.3 \%$ supported the notion of adapting new TM. Merely, $2.2 \%$ and $8.7 \%$ respectively disagreed to these views. Additionally, q2.2.7 was used to tackle the use of commu- 
nicative approach in teaching as a sensitive point in the field of teaching-learning language. The results showed that $89.1 \%$ agreed to use more communicative approach in their teaching, while $8.7 \%$ opposed the idea indicating that they prefer following the traditional TM (e.g., Grammar Translation Method). It might be due to the respondents' illiteracy (i.e., could not understand the meaning of communicative approach) in testing, $2.2 \%$ undecided to be with or against this idea (in all the tables this type of response is symbolized with $(*))$. The last item q2.2.8 sought if the participants devoted themselves to organize more exam practices. The results revealed that $95.7 \%$ agreed that the change they would have in the 3rd secondary, comparing to the other lower classes, could be organizing more mock tests and carrying out more practices on these tests in the classroom.

This revealed that the results elicited from the quantitative data positively support the findings of the qualitative findings where both reflected the influence of the GSEE on the TM. Table 4 shows the frequencies, mean (M) and standard deviation (SD) entailed with the Confidence Interval for Mean (95\%) as statistical values of the first theme, TM, reflecting the teachers answers to the above questions.

Table 4: Descriptive Statistics $1(\mathrm{~N}=46) \mathrm{SA}=$ Strongly Agree, $\mathrm{A}=$ Agree, *= Undecided, $\mathrm{D}=\mathrm{Disagree}, \mathrm{SD}=\mathrm{Strongly}$ Disagree

\begin{tabular}{|c|c|c|c|c|c|c|}
\hline \multirow{2}{*}{ Question } & \multicolumn{2}{|c|}{ Participants' Responses } & \multirow{2}{*}{$\mathbf{M}$} & \multirow{2}{*}{ SD } & \multicolumn{2}{|c|}{ 95\% Confidence Interval for Mean } \\
\hline & SA/ A & SD/D & & & Lower Bound & Upper Bound \\
\hline $\begin{array}{l}\text { q2.2.1 To teach according to the test } \\
\text { format }\end{array}$ & $\begin{array}{l}33 \\
(71.7 \%)\end{array}$ & $\begin{array}{l}13 \\
(28.2 \%)\end{array}$ & 2.46 & 1.20 & 2.10 & 2.81 \\
\hline $\begin{array}{l}\text { q2.2.2 To focus on grammar and vo- } \\
\text { cabulary }\end{array}$ & $\begin{array}{l}44 \\
(95.6 \%)\end{array}$ & $\begin{array}{l}2 \\
(4.3 \%)\end{array}$ & 1.76 & .67 & 1.56 & 2.96 \\
\hline $\begin{array}{l}\text { q2.2.3 To put more stress on role play } \\
\text { and group discussions }\end{array}$ & $\begin{array}{l}24 \\
(84.4 \%)\end{array}$ & $\begin{array}{l}7 \\
(15.2 \%)\end{array}$ & 2.00 & 1.03 & 1.69 & 2.31 \\
\hline $\begin{array}{l}\text { q2.2.4 To put more emphasis on read- } \\
\text { ing and writing skills }\end{array}$ & $\begin{array}{l}41 \\
(89.2 \%)\end{array}$ & $\begin{array}{l}5 \\
(10.9 \%)\end{array}$ & 1.78 & .98 & 1.49 & 2.08 \\
\hline $\begin{array}{l}\text { q2.2.5 To encourage more students' } \\
\text { participation in class }\end{array}$ & $\begin{array}{l}45 \\
(97.8 \%)\end{array}$ & $\begin{array}{l}1 \\
(2.2 \%)\end{array}$ & 1.59 & .71 & 1.37 & 1.80 \\
\hline q2.2.6 To adapt new teaching methods & $\begin{array}{l}42 \\
(91.3 \%)\end{array}$ & $\begin{array}{l}4 \\
(8.7 \%)\end{array}$ & 1.87 & .75 & 1.65 & 2.09 \\
\hline $\begin{array}{l}\text { q2.2.7 To use a more communicative } \\
\text { approach in my teaching }{ }^{(*)}\end{array}$ & $\begin{array}{l}41 \\
(89.1 \%)\end{array}$ & $\begin{array}{l}4 \\
(8.7 \%)\end{array}$ & 1.87 & .90 & 1.60 & 2.14 \\
\hline $\begin{array}{l}\text { q2.2.8 To organize more exam prac- } \\
\text { tices }\end{array}$ & $\begin{array}{l}44 \\
(95.7 \%)\end{array}$ & $\begin{array}{l}2 \\
(4.3 \%)\end{array}$ & 1.63 & .87 & 1.37 & 1.89 \\
\hline
\end{tabular}

\subsection{GSEE Washback on Content Assessment (CA)}

For most of the teachers, grammar lessons are the most important ones in the 3rd secondary classes. However, this kind of studiousness is not for the sake of grammar as an important element in learning the language structure but because GSEE is a grammarbased test. Teacher AM supported this notion stating that "the exam influences the content because it makes the content fully concentrated on the grammar points because about $80 \%$ of the exam is grammar." In this case, the teachers found it easy to teach grammar because other subjects, such as spoken or listening, may be difficult or boring for them and for students, especially when they are not included in the exam.

More surprisingly, some teachers viewed that the content can be put aside and a collection of ten-or-more models of the GSEE should be taught instead. They claimed that because the test designers followed almost the same style for every year, and the difference was only in the content of the questions, the most important thing was to teach students the way of the test. For them, teaching the course became subsidiary and only those lessons which were more relevant to the test could be taught. For example, teacher HM confidently narrated her story for preparing her students for the GSEE when she said that she teaches English for 13 years and she teaches the students collections of tests instead of the course book.

On the contrary, some teachers believed that the course content must be taught to the students with more focus on the lessons and the exercises which are more relevant to the GSEE. For these teachers, learning the language is also another duty and the load on them is heavier because they have to consider time besides the students' motivation. Teacher EH emphasized that "the teachers should cover the entire subject in a period of six months where teachers need to do their best to cover all topics, but more focus should be paid on the topics more related to the test."

This might be the closest approach to the syllabus objectives but the problem is the readiness of the teachers and the learners to cover the whole course. This reflects the washback effect of the GSEE on the content assessment, when only the lessons related to the paper-and-pen skills, for example reading and writing, are prominently considered and aural-oral skills, such as listening and speaking, are of less importance. Teacher KT reported that "some teachers focus on some points in the book, for example, grammatical points. This is a kind of influence on the content."

Following the same process in analysing the qualitative findings, content assessment (CA) was also the second theme for which eight items were designed as responses to the leading question in quantitative data (questionnaire). The leading question was 'what kind of extra work or pressure do you think the GSEE can put on you in your teaching regarding the content you are teaching?' To answer this question, respondents followed the same they did for the TM question (i.e., following the five-point Likert scale of agreement). Methodically, the eight statements were numbered as q2.3.1-8 following the same sequence of the previous theme.

Accordingly, q2.3.1 inquired whether the teachers executed more lesson preparations due to the impact of the GSEE on them as 3rd secondary class teachers. The results revealed that $82.6 \%$ did more lesson preparations for the 3rd secondary students compared to just $15.2 \%$ of the respondents who disagreed to make additional lesson preparations and only $2.2 \%$ undecided for both. This result makes it important to mention that the majority of the teachers think seriously about the GSEE being influenced by its washback effect due to its importance to their students. More importantly, $93.5 \%$ of the teachers prepared more materials for the students according to q2.3.2, while $6.5 \%$ duly followed the syllabus. Again, this result is significant and it supports most of the findings from the interviews. Closer to this, q2.3.3 showed that $89.2 \%$ considered revising the existing materials as one way for helping students pass the GSEE, where only $10.9 \%$ opposed this point which means that they prefer preparing more materials for students rather than just moving around the existing materials. Q2.3.4 probed into the respondents' views on teaching only the topics similar or closer to those normally included in the GSEE. The results showed that $50 \%$ of the participants agreed to that, while $47.8 \%$ opposed this opinion. This proportion is somehow acceptable but still unsatisfactory since a half of the teachers supported the idea of teaching only the topics related to the test and this goes in parallel with the findings of the qualitative data stating that teachers mostly prefer to teach according the GSEE. Hence, the predomination 
of the washback effect appeared clearly due to the ignorance of the objectives of the syllabus and teaching according to the test.

On the other hand, $93.5 \%$ of the respondents supported the notion of going through the textbook excises to help students overcome the difficulty of the exam, while $6.5 \%$ of them disagreed to this issue. Not far from this proportion, through q2.3.6, it appeared that $91.5 \%$ of the participants reinforced the notion of teaching grammar rules and vocabulary extensively. This indicates that the teachers were aware of the importance of grammatical rules and vocabulary for the GSEE as a grammar-based test. Conversely, a minor percentage $8.7 \%$ disagreed to this issue, which indicates that some teachers considered language skills but this number is uncourageous compared to those who buttressed grammar and vocabulary due to their importance for the exam. Based on these results, it could be stated that the vast majority of the teachers were obliged to teach to the test and to do whatever could be valuable and beneficial for students to survive from the GSEE, see Table 2 .

Table 5: Descriptive Statistics $1(\mathrm{~N}=46) \mathrm{SA}=$ Strongly Agree, $\mathrm{A}=$ Agree, *= Undecided, $\mathrm{D}=\mathrm{Disagree}, \mathrm{SD}=\mathrm{Strongly}$ Disagree

\begin{tabular}{|c|c|c|c|c|c|c|}
\hline \multirow{2}{*}{ Question } & \multicolumn{2}{|c|}{ Participants' Responses } & \multirow{2}{*}{$\mathbf{M}$} & \multirow{2}{*}{ SD } & \multicolumn{2}{|c|}{ 95\% Confidence Interval for Mean } \\
\hline & SA/ A & SD/D & & & Lower Bound & Upper Bound \\
\hline q2.3.1 Doing more lesson preparations ${ }^{(*)}$ & $\begin{array}{l}38 \\
(82.6 \%)\end{array}$ & $\begin{array}{l}7 \\
(15.2 \%)\end{array}$ & 2.09 & 1.07 & 1.77 & 2.41 \\
\hline q2.3.2 Preparing more materials for students & $\begin{array}{l}43 \\
(93.5 \%)\end{array}$ & $\begin{array}{l}3 \\
(6.5 \%)\end{array}$ & 1.80 & .74 & 1.58 & 2.03 \\
\hline $\mathrm{q} 2.3 .3$ Revising the existing materials & $\begin{array}{l}41 \\
(89.2 \%)\end{array}$ & $\begin{array}{l}5 \\
(10.9 \%)\end{array}$ & 1.93 & .85 & 1.68 & 2.19 \\
\hline $\begin{array}{l}\text { q2.3.4 Teaching only the topics similar to those } \\
\text { normally included in the GSEE }\end{array}$ & $\begin{array}{l}23 \\
(50 \%)\end{array}$ & $\begin{array}{l}22 \\
(47.8 \%)\end{array}$ & 2.91 & 1.34 & 2.52 & 3.30 \\
\hline q2.3.5 Going through the textbook exercises & $\begin{array}{l}43 \\
(93.5 \%)\end{array}$ & $\begin{array}{l}3 \\
(6.5 \%)\end{array}$ & 1.96 & .75 & 1.73 & 2.18 \\
\hline $\begin{array}{l}\text { q2.3.6 Teaching grammar rules and vocabulary } \\
\text { extensively }\end{array}$ & $\begin{array}{l}42 \\
(91.5 \%) \\
\end{array}$ & $\begin{array}{l}4 \\
(8.7 \%)\end{array}$ & 1.87 & .88 & 1.61 & 2.13 \\
\hline $\begin{array}{l}\text { q2.3.7 Focusing on reading and writing because } \\
\text { they carry } 80 \% \text { of the total marks }\end{array}$ & $\begin{array}{l}40 \\
(87 \%)\end{array}$ & $\begin{array}{l}6 \\
(13 \%)\end{array}$ & 1.87 & 1.08 & 1.55 & 2.19 \\
\hline q2.3.8 Practicing the tests of the previous years & $\begin{array}{l}40 \\
(87 \%)\end{array}$ & 6 & 1.96 & 1.05 & 1.64 & 2.27 \\
\hline
\end{tabular}

To conclude, the teachers' point of views about CA could be summarized into three notions. The first is those who see that it is the only test, which must be highly considered and the course content should follow the test. In other words, they regarded GSEE as independent and the content as the dependent factor. Hence, one can elicit how the washback phenomenon makes teaching-learning processes controversial or even contradictory because, according to the tradition, exams follow courses and not vice versa. The second is the view which leans towards the course content as a main source for supplying students with all required information for successfully answering the GSEE questions. Here, the issue is just at the opposite of the first notion where the course plays the role of the independent factor and the test is just dependent. However, another issue could be raised such as the time insufficiency and the learners' consciousness about the exam. The third viewpoint pragmatically makes a balance between the two previous views arguing that the most relevant lessons to the GSEE must be taught.

\subsection{GSEE Washback on Teachers' Attitudes (TA)}

Due to the impact GSEE has on teachers, as appeared throughout the issues discussed above, the need for investigating their attitudes becomes more urgent. It could be said that a teacher has no significant role in determining the direction of the classroom activities in the light of the prescribed syllabus. Even if he/she has the enthusiasm to make his students acquire the language skills, the test is standing as an obstacle in the way. Hence, a great impact can be created on the teachers' attitudes especially when they know that they have no role in the test construction. Teacher HY warned that "this will affect the teachers' attitudes where a teacher will be as a person with no personality. He is a follower."

What makes the matter worse is when a teacher knows that he is impaled on the horns of a dilemma by the GSEE having no choice but to teach to the test. In other words, the teacher is almost ignored from participating in the exam design and, on the other hand he has no rights on the students since the test is assessed outside the school; by the Ministry. In this way, students are free having no obligation to the teachers and their relationship with the teacher is just a test-preparation relation. Teacher KT obviously explained

this point saying, "when teaching the lower grades, students have fear from the teacher because he has ability to give them marks but in third $3^{\text {rd }}$ secondary, a teacher has to work hard to control students because he cannot banish them with marks."

Another important point that could be mentioned here is the choice of the teachers who would teach the third secondary level. Normally, school administration chooses the best teachers for teaching this level not because they were the best but because this would lead to better marks in the exam. Hence, a teacher might feel that he was in a trap where many problems could happen for him. The first is the students who must be controlled and there is only patience and experience that can help in controlling classes and no punishments could be executed on the students so that they became obliged to the classroom activities. The second is reputation of the teacher. By choosing a teacher to teach the $3^{\text {rd }}$ secondary level, it means that it is also a test for him/her. Therefore, the teacher is under the influence of the GSEE but in indirect way because he/she has to struggle to help students get high marks and this will be good for his/her reputation. The last is the teacher's relationship with his colleagues. To explain this point, choosing a particular teacher from a group of teachers means that he is the best among them. This creates a kind of dissatisfaction among the teachers towards him and makes him at risk to survive in making good relationship with others and at the same time tries to achieve the desired goal for both school administrations as well as the students. Teacher EH pointed out that "the attitude of the teacher is related to the exam, he must be careful of the test he must be very interested in the exam. He must prepare himself and he must be very optimistic towards the test."

Again, it seems that GSEE is the ultimate goal for which all efforts must be intensified. The reason beyond that is an important indicator of the teacher's merit when students managed to get high grades in the GSEE. In this way, GSEE becomes the overridden concern for the teachers as it does for the students and the remaining stakeholders. Teacher AD proved this point when she states that "the first thing to think of while introducing English language to the students is the exam, because if many of your students fail, it is an indicator that the ways of teaching are not good."

Accordingly, the prospect of negative washback loomed large. The sound of learning English as a language disappeared and the only required goal would be 'marks.' The teacher has no choice but to teach according to the test. Many lessons, though they were beneficial for language learning, would be omitted and the teacher is obliged to teach only the lessons related to the GSEE. Teacher 
DH drearily spoke about this issue when she stated that "GSEE affects the teachers' attitudes when she finds herself forced to do everything for the sake of the test." This reflects the most appropriate meaning of the washback phenomenon according to the applied linguists' definition. Because of the GSEE, teachers do things they would not otherwise do. In other words, whether satisfied with the test or not, the teacher should do whatever to make the students obtain high marks in the GSEE.

In relation, TA was the third theme touched upon in the teachers' questionnaire. For this purpose, eight questions (all headed by "what is your opinion of ...," were drawn seeking their opinions of agreement and disagreement about the impact of the GSEE on the attitudes of the English teachers. The first question q2.4.1 inquired if the teachers agreed that GSEE has a positive influence on teaching (e.g., it helps focus on teaching and provide feedback on teaching). The results showed that $78.2 \%$ agreed to this issue, $19.5 \%$ disagreed and only $2.2 \%$ gave no decision to both of the agreement choices. In relation to this, q2.4.2 reflected that the same proportion $(78.2 \%)$ of the respondents agreed that GSEE reflecting the goals and the objectives of the secondary school curriculum requirement, while $21.7 \%$ came against this opinion. What could be elicited here is that though the majority of the respondents who gave an opposite views of what was elicited through the qualitative data, when most of the interviewees stated that GSEE does not reflect the goals and the objectives of the secondary school curriculum requirements, but $21.2 \%$ could be considered as a significant proportion. It could be recognized as a supporting proof to the interviewees' viewpoints.

Furthermore, q2.4.3 inquired if the teachers viewed that learning a language is to accumulate the knowledge of grammar, vocabulary, structure and rules as in the case of the GSEE. The purpose behind this question was to find out how teachers were aware of the predominance of grammar and the other structural elements of the language and, at the same time, how the other language skills (e.g., speaking and listening skills) were neglected by the test. Similar to q2.4.1, the results revealed that $78.2 \%$ agreed to this point, while $19.5 \%$ disagreed and $2.2 \%$ was outlier due to the indecision of one respondent. What makes the problem worse, is the teachers' attitudes (TA) towards the test. When considering this issue seriously, one could see the contradictory views of the teachers regarding the GSEE. To explain, throughout their responses to q2.4.1, it is obvious that they look at the exam positively. In the same time, they viewed that it is almost a grammar-based test as seen in the results of q2.4.3. This might be due to their belief that grammar and vocabulary are the most important components of the exam and, for them, they could be afforded easily and this gives a clear answer why the majority of the teachers viewed that it is a positive influence on teaching which, in turn, indicates that TA towards the GSEE is positive.

Unlike all the items described above, q2.4.7 was out of ordinary. In a sense, the proportion of disagreement was higher $52.5 \%$, while only $43.5 \%$ of the respondents agreed that test scores of the GSEE are appropriate indicators of students' English ability. This does indicate that the majority of the teachers are not satisfied with test because it does not represent their real English ability. It is also important to mention here that the mean $(M)$ is the highest among all the eight items related to the TA theme reaching 3.15 and the confidence interval for mean $(95 \%)$ is bounded between 2.77 and 3.54. Additionally, due to the sensitivity of this statement $4.3 \%$ was the proportion of the participants who undecided to respond positively or negatively.

The last question q2.4.8 reflected the TA towards the GSEE where the participants were asked if they agree that the main goal of the teacher is to help students pass the GSEE. A total of 54.3\% agreed that their main objective was to help students pass the exam compared to $43.5 \%$ who disagreed to this point and only $2.2 \%$ undecided to both. Hence, TA factor emerged as it is predominated by the GSEE and the teachers are in a situation in which they have to serve the exam more than the syllabus, see Table 6.

Table 6: Descriptive Statistics 1 ( $\mathrm{N}=46) \mathrm{SA}=$ Strongly Agree, $\mathrm{A}=$ Agree, *= Undecided, $\mathrm{D}=\mathrm{Disagree}, \mathrm{SD}=\mathrm{Strongly}$ Disagree

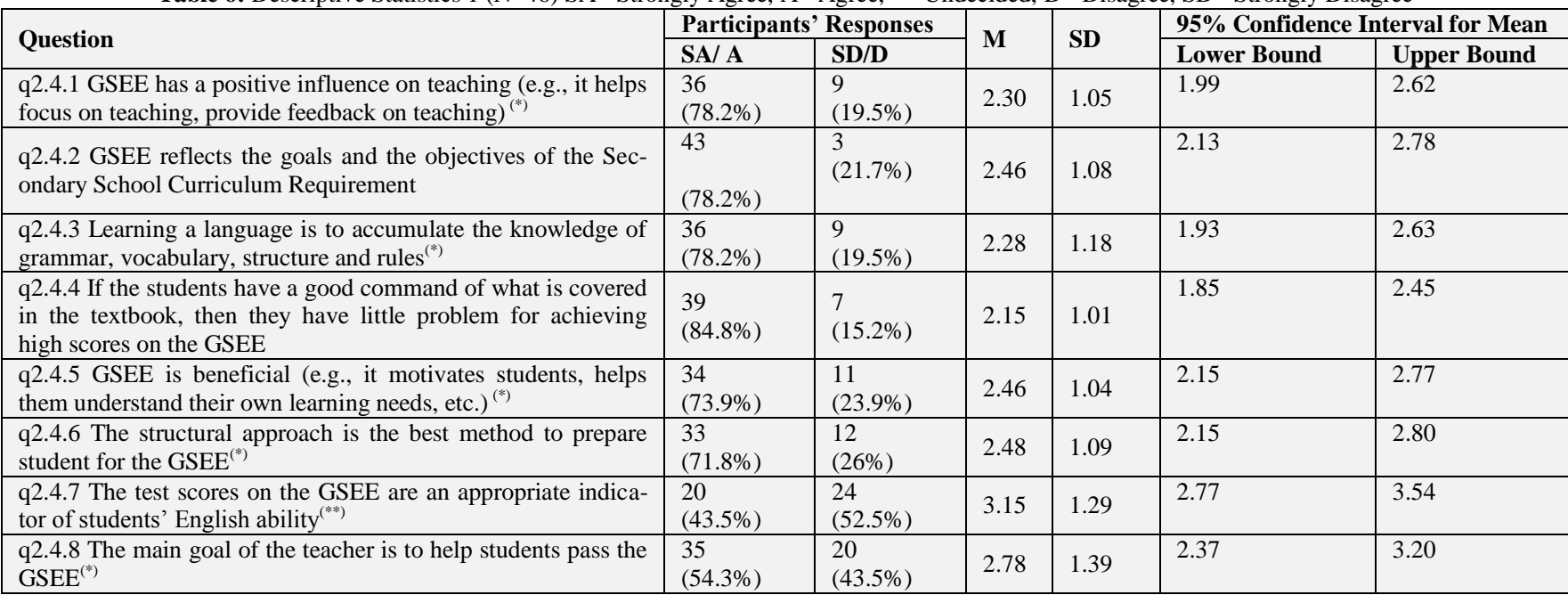

In sum, whether the teachers like or dislike the GSEE, it is their duty to do their best to help students pass the exam. In other words, the teacher is put in a situation where he must strike a balance between his ambition of making his students acquire the language and help students gain high grades in the GSEE.

\subsection{GSEE Washback on the Teachers' Motivation (TMO)}

evaluation are in the hand of the High Committee of Examination (HCE). Throughout carrying out the $3^{\text {rd }}$ secondary classroom observations and the interviews with the teachers, it was found that most of the teachers were depressed and they felt as they were enslaved to the GSEE.

Furthermore, there is a fateful relationship between the teachers and the GSEE where the findings showed that their motivation is instrumental. In other words, if students got high marks in the GSEE, this would be highly appreciated form the perspective of the test stakeholders. On the contrary, if the students failed or got low marks the teacher would be disdained or disparaged and his reputation would be negatively affected. This cannot happen to teachers of the other levels who actively teach the language not to

the test. They have the right to design tests for their students in the

the teachers asserted that GSEE has a great in on the teachers' motivation. Certainly, the value of motivation is expected to be negative because the teachers have had no choice but to teach to the test. In other words, the teachers' role in the exam construction is passive and the test control, distribution and 
light of what has been taught throughout the year as a kind of school based assessment (SBA). Hence, it could be stated that the teachers of the $3^{\text {rd }}$ secondary level were innocent victims of the GSEE washback.

What makes the matter worse is that the teacher in the $3^{\text {rd }}$ secondary class almost forgot the main objective of the syllabus (i.e., language learning). This may be due to the GSEE which plays a vital role in the direction of the TMO. To clarify, the positivity and the negativity of the TMO essentially depend on the results of the GSEE whereas in the other levels (i.e., previous levels) the TMO value is related to teaching and learning of the language This indicates that the GSEE may lead to a purely instrumental or utilitarian motivation where teacher would not think about the language learning but rather about the test marks. An obvious comment on this regard is by teacher DH confirmed that "the test itself is the most influencing thing for teaching because the teacher is forced to do things which would be used by the students in this test."

On the other hand, most of the teachers (14) tried to reasonably argue that the GSEE might positively affect the TMO but to some extent. Instead, they proved that the effect could mostly be harmful rather than beneficial. Additionally, they argued that it created an environment for negative washback by harnessing all potentials and capabilities in the classroom just for the GSEE. Hence, almost no attention could be paid to learning the language. Teacher AM dramatically shed some light on the effect of the GSEE on the TMO when describing that "it is not very effective motivation because it just puts the teachers and also the students on a corner for the exam not for acquiring the language."

Furthermore, some teachers claimed that the effect of the GSEE on the TMO could significantly be due to the teachers' qualifications and experiences. Those who were highly qualified and had long experience of teaching the $3^{\text {rd }}$ secondary classes, might not have any effect by the GSEE neither positively nor negatively. According to this point of view, washback effect could only occur on the junior of fresh teachers. Consequently, this proves the reasons beyond choosing the most qualifies and experienced teachers for teaching the $3^{\text {rd }}$ secondary level. As an example, teacher $A D$ assured that "he always keeps the idea of the exam in mind and so if there is a motivation, it is only for the sake of helping his students pass the exam."

Shifting to the quantitative data, TMO was the fourth theme for which the respondents were asked to give their opinion through responding to eight statements (i.e., q2.5.1 - q2.5.8) headed by the leading question: 'what are the teaching factors that could be more motivated for teachers?' Following the same method used to investigate the washback effect of the GSEE, the respondents were requested to scale their answer to the questions according to the five-point Likert scale of agreement. However, during analyzing the data SA and A was dealt with as one indicator of positive response (agreement) while SD and D was considered as one reply of disagreement. The respondents' indecision $(\mathrm{N})$ was also considered for two reasons. The first was to know how such an item was clear for them. The second was to elicit if the respondents were motivated and committed to provide beneficial feedback regarding the GSEE as a serious issue for them.
The first question q2.5.1 inquired if the GSEE motivates teachers to improve their methodology in teaching English. The results showed that $89.1 \%$ agreed to that, while only $10.9 \%$ disagreed and this indicates that they considered the test as it demotivates teachers towards teaching making them teach for testing rather for learning the language. Having a precise look at those who agreed that the GSEE motivate teachers to improve their methodologies in teaching learners, it could be found that they considered the term 'language learning' as grammar and vocabulary only because the test is almost built of these two language elements. They might forget that language is beyond such partial understanding and it can only be acquired if it is taken as a whole.

Opposite to the first statement, the second question (q2.5.2) was established to probe if the respondents viewed that the GSEE discourages the use of advanced teaching methodologies. With reference to the results, it was found that $45.7 \%$ agreed to that, while $52.1 \%$ disagreed. Though the proportion of those who agreed to this issue were less than those who disagreed, but still the difference between the two proportions was not significant (only 6.3\%) indicating that the TMO towards the GSEE was not positive. However, when they were asked if the test creates positive attitudes towards English teaching (q2.5.3), 71.7\% agreed and 28.3\% disagreed. Likewise, q2.5.4 inquired if the GSEE helps upgrade teaching and learning. The results revealed that $78.2 \%$ of the respondents agreed to this point, while $21.7 \%$ disagreed. The same proportions of agreement and disagreement were seen in the results of q2.5.5 and q2.5.6 which were introduced to elicit if the GSEE makes teachers work in line with the teaching objectives and if it motivates teachers to prepare more materials for students respectively.

On the contrary, $64.2 \%$ of the respondents agreed that the GSEE forces teachers to teach to the test according to q2.5.7, when $34.8 \%$ disagreed to this idea. This indicates that there was ambiguity in the TMO regarding the exam and the reason behind that might be due to the unconsciousness of the influence of the GSEE. To verify, when the respondents were asked about the benefits of the test to their teaching, they reacted to the questions positively (i.e., they gave positive agreement). On the other hand, when they were asked about the effect of the exam on their teaching (e.g., whether the GSEE forced them to teach to the test), they responded that they agreed which means that they have been negatively affected by the test because it has forced them to teach according its content

The last question q2.5.8 sought the respondents' opinion about the GSEE and whether it provides feedback on teaching. The results showed that $87 \%$ agreed and $13 \%$ disagreed. According to the results, one could state that the TMO factor is under the influence of the GSEE washback because when they agreed that it supplies feedback on their teaching, they meant they considered it and they did pay much attention towards its effect being the tool that might reflect how their teaching was good or bad. Hence, it could be noticed that the results of the items dealt with the theme of TMO come in line with the findings of the qualitative data in proving that the TMO, as an important element on the part of teachers, is affected by the GSEE washback, see Table 7 .

Table 7: Descriptive Statistics $1(\mathrm{~N}=46) \mathrm{SA}=$ Strongly Agree, $\mathrm{A}=$ Agree, *= Undecided, $\mathrm{D}=\mathrm{Disagree}, \mathrm{SD}=\mathrm{Strongly}$ Disagree

\begin{tabular}{|c|c|c|c|c|c|c|}
\hline \multirow{2}{*}{ Question } & \multicolumn{2}{|c|}{ Participants' Responses } & \multirow{2}{*}{$\mathbf{M}$} & \multirow{2}{*}{ SD } & \multicolumn{2}{|c|}{ 95\% Confidence Interval for Mean } \\
\hline & SA/A & SD/D & & & Lower Bound & Upper Bound \\
\hline $\begin{array}{l}\text { q2.5.1 It motivates teachers to improve their method- } \\
\text { ology in teaching English }\end{array}$ & $\begin{array}{l}41 \\
(89.1 \%)\end{array}$ & $\begin{array}{l}5 \\
(10.9 \%) \\
\end{array}$ & 1.80 & .85 & 1.55 & 2.06 \\
\hline $\begin{array}{l}\text { q2.5.2 It discourages the use of advanced teaching } \\
\text { methodologies }{ }^{(*)}\end{array}$ & $\begin{array}{l}21 \\
(45.7 \%)\end{array}$ & $\begin{array}{l}24 \\
(52.1 \%)\end{array}$ & 3.00 & 1.21 & 2.64 & 3.36 \\
\hline $\begin{array}{l}\text { q2.5.3 It creates a positive attitude towards English } \\
\text { teaching }\end{array}$ & $\begin{array}{l}33 \\
(71.7 \%)\end{array}$ & $\begin{array}{l}13 \\
(28.3 \%)\end{array}$ & 2.59 & 1.14 & 2.25 & 2.93 \\
\hline q2.5.4 It helps upgrade teaching and learning & $\begin{array}{l}36 \\
(78.2 \%)\end{array}$ & $\begin{array}{l}10 \\
(21.7 \%)\end{array}$ & 2.35 & .82 & 2.10 & 2.59 \\
\hline $\begin{array}{l}\text { q2.5.5 It makes teachers work in line with the teach- } \\
\text { ing objectives }\end{array}$ & $\begin{array}{l}36 \\
(78.3 \%)\end{array}$ & $\begin{array}{l}3 \\
(21.7 \%)\end{array}$ & 2.46 & .95 & 2.17 & 2.74 \\
\hline q2.5.6 It motivates teachers to prepare more materials & 36 & 10 & 2.24 & 1.07 & 1.92 & 2.56 \\
\hline
\end{tabular}




\begin{tabular}{|l|l|l|l|l|l|}
\hline for students & $(78.2 \%)$ & $(21.8 \%)$ & & \\
\hline q2.5.7 It forces teachers to teach to the test & $\begin{array}{l}30 \\
(65.2 \%)\end{array}$ & $\begin{array}{l}16 \\
(34.8 \%)\end{array}$ & 2.50 & 1.32 & 2.11 \\
\hline $\begin{array}{l}\text { q2.5.8 It provides feedback on teaching (e.g., posi- } \\
\text { tive/negative) }\end{array}$ & $\begin{array}{l}40 \\
(87 \%)\end{array}$ & $\begin{array}{l}6 \\
(13 \%)\end{array}$ & 2.20 & .91 & 1.93 \\
\hline
\end{tabular}

In sum, according to the excerpts quoted above and significant results of the questionnaire, the effect on the TMO is because of the pressure of the GSEE. In this way, teachers became very vulnerable to the washback effect resulted by the test and because they were metaphorically enslaved by the GSEE, they could not teach the language but rather the test itself.

\section{Conclusion}

To conclude, this study confirms that high-stakes language tests, such as GSEE, may not necessarily generate what their designers and administrators tended to achieve (i.e., positive washback) because unintended consequences may occur. The study contributes to developing the teachers understanding of the reasons that hinder the occurrence of the desired washback, and, in the meanwhile, may cause unintended harmful washback. Furthermore, the study came up with the conclusion that unavoidable mismatch may occur between the desired objectives of the curriculum and the real achievement of these objectives through the use of appropriate teaching methods due the test harmful washback on the teachers. It is hoped that this study can provide English teachers with a basic reflection about language teaching in the light of the desired objectives of the syllabus. Since the prevailing teaching methods adopted by Yemeni secondary school English teachers, as reflected in this study, do not support them to accomplish the goals sought by the English Curriculum, this study would prove useful resource for teachers to modify their teaching methods to meet the students' needs of language communicative proficiency. Supporting the findings of $(9,14,16-22)$, the present study recommends that changing teaching methods occurs as gradual progress and they are the product of long-term comprehension of various contexts for teaching.

\section{References}

[1] Prodromou L. Bilingua Speaker'of English. English in the world Global rules, global roles. 2006:51.

[2] Alderson JC, Wall D. Does washback exist? Applied linguistics. 1993;14(2):115-29.

[3] Bailey KM. Working for washback: A review of the washback concept in language testing. Language testing. 1996;13(3):257-79.

[4] Biggs J. Assumptions underlying new approaches to educational assessment: implications for Hong Kong. 課程論壇. 1995.

[5] Gates S. Exploiting washback from standardized tests. Language testing in Japan. 1995:101-6.

[6] Brown JD. Extraneous variables and the washback effect. JALT Testing \& Evaluation SIG Newsletter. 2002;6(2):10-3.

[7] Cheng L, Curtis A. Washback or backwash: A review of the impact of testing on teaching and learning. Washback in language testing: Research contexts and methods. 2004:3-17.

[8] Messick S. Validity and washback in language testing. ETS Research Report Series. 1996;1996(1).

[9] Tayeb YA, Aziz MSA, Ismail K, Khan ABMA. The washback effect of the general secondary english examination (GSEE) on teaching and learning. GEMA; Online Journal of Language Studies. 2014;14(3):83-103.

[10] Nguyen N, Griffin P, Izard J. Towards Beneficial Washback Effect of a Test. Vietnam National University, University of Melbourne, and Australian Council for Educational Research. 2008.

[11] Cheng L, Watanabe Y. Washback in language testing: Research contexts and methods: Routledge; 2004.

[12] Fröhlich M, Spada N, Allen P. Differences in the communicative orientation of L2 classrooms. Tesol Quarterly. 1985:27-57.

[13] Watanabe Y. Methodology in washback studies. Washback in language testing: Research contexts and methods. 2004:19-36.

[14] Cheng L. Changing language teaching through language testing: A washback study: Cambridge University Press; 2005.
[15] Salehi H, Yunus MM. The washback effect of the Iranian universities entrance exam: Teachers' insights. GEMA: Online Journal of Language Studies. 2012;12(2 (special edition)):609-28.

[16] Saif S. Theoretical and empirical considerations in investigating washback: A study of ESL/EFL learners: National Library of Canada = Bibliothèque nationale du Canada; 2001.

[17] Shibliyev J, Gilanlıŏlu İ. Language Testing and Assessment: An Advanced Resource Book. ELT journal. 2009;63(2):181-3.

[18] Saville N. Developing a model for investigating the impact of language assessment. Research Notes. 2010;42:2-8.

[19] Wang J. A study of the role of the 'teacher factor'in washback: McGill University; 2010.

[20] Özmen KS. Washback effects of the inter-university foreign language examination on foreign language competences of candidate academics. Novitas-ROYAL (Research on Youth and Language). 2011;5(2):215-28.

[21] Onaiba E-M, Mustafa A. Investigating the washback effect of a revised EFL public examination on teachers' instructional practices, materials and curriculum: University of Leicester; 2014.

[22] Baksh A, Mohd Sallehhudin A, Tayeb Y, Norhaslinda H. SOCIAL SCIENCES \& HUMANITIES. 2016. 